\title{
Mathematical Models for the Skin to Lumbosacral Epidural Distance in Dogs: A Cadaveric Computed-Tomography Study
}

\author{
Tsim Christopher Sun *(D), Mara Schier (D), Michelle Pui Yan Lau and Fernando Martinez-Taboada \\ Sydney School of Veterinary Science, University of Sydney, Camperdown, NSW 2050, Australia; \\ mara@maraschier.com.au (M.S.); mpylau93@gmail.com (M.P.Y.L.); fer_m_taboada@hotmail.com (F.M.-T.) \\ * Correspondence: christopher.sun@sydney.edu.au
}

check for updates

Citation: Sun, T.C.; Schier, M.; Lau, M.P.Y.; Martinez-Taboada, F.

Mathematical Models for the Skin to Lumbosacral Epidural Distance in Dogs: A Cadaveric ComputedTomography Study. Animals 2021, 11, 2974. https://doi.org/10.3390/ ani11102974

Academic Editors: Angela Briganti and Hamaseh Tayari

Received: 20 September 2021 Accepted: 13 October 2021 Published: 15 October 2021

Publisher's Note: MDPI stays neutral with regard to jurisdictional claims in published maps and institutional affiliations.

Copyright: (c) 2021 by the authors. Licensee MDPI, Basel, Switzerland. This article is an open access article distributed under the terms and conditions of the Creative Commons Attribution (CC BY) license (https:/ / creativecommons.org/licenses/by/ $4.0 /)$.
Simple Summary: Epidural anaesthesia is readily performed in the lumbosacral area in dogs that are undergoing surgery of the hindlimbs or the abdomen. Common techniques that are used to identify the epidural space rely on subtle changes in tactile and audible sensations which are challenging for less experienced clinicians. Research in humans suggest that mathematical equations that are derived from body surface parameters may improve the success of epidural space identification. In a previous study by this research group, we developed two mathematical equations from computed tomography (CT) measurements using dog surface parameters and a body condition score to predict the skin to lumbosacral epidural space. In this study, we aimed to validate the equations in dog cadavers against a gold standard technique (epidurography). For one equation, the use of the occipital-coccygeal length and body condition score resulted in a high degree of correlation and agreement with the skin to lumbosacral epidural space of the cadavers. Future studies will determine whether the knowledge of the skin to lumbosacral epidural space distance prior to needle placement improves the success of epidural space identification.

Abstract: This study aimed to validate previously published computed tomography (CT) derived mathematical equations with the true skin to lumbosacral epidural distance (SLED) in dog cadavers. Phase 1: The lumbar region of $11 \mathrm{dog}$ cadavers were scanned in sternal recumbency to determine the effect of cranial, neutral, and caudal pelvic limb positioning on the CT derived lumbosacral epidural distance (CLED). Phase 2: The epidural space was determined using contrast epidurography, and the SLED was analysed against the mathematical equations using a body condition score (BCS) and either the cadaveric occipital-coccygeal length (OCL) (Equation (1): $=7.3+0.05^{*} \mathrm{OCL}+16.45^{*} \mathrm{BCS}$ ) or the ilium wing distance (IWD) (Equation (2): $=3.5+0.56^{*} \mathrm{IWD}+16.6^{*} \mathrm{BCS}$ ). There were no differences detected between the pelvic limb positions and the CLED. Both equations demonstrated strong correlations (Equation (1): $r=0.7196$; Equation (2): $r=0.7590$ ) with the SLED. The level of agreement was greater for Equation (1) than with Equation (2) (concordance coefficient 0.6061 and 0.3752 , respectively). Equation (1) also demonstrated a closer fit to the concordance line compared with Equation (2) (bias correction factor 0.8422 and 0.4960 , respectively). Further studies in live anaesthetised dogs will help to determine the usefulness of the pre-procedural knowledge when performing lumbosacral epidurals.

Keywords: epidural; lumbosacral; mathematical; modelling; locoregional; anaesthesia; computed tomography; ligamentum flavum; epidurography

\section{Introduction}

Successful epidural anaesthesia relies on the accurate placement of the needle through the skin into the epidural space, but regardless of the method used to identify the epidural space, clinicians are unaware of how far the needle must travel. Most veterinary clinicians performing lumbosacral epidurals do so without any radiographic assistance and instead blindly select the needle trajectory and the final target. Mathematical models have been 
used in human anaesthesia to predict the distance that is required to enter the epidural space [1,2]. In particular, the relationship between anthropometric variables and the body mass index have been shown to have positive correlations with the skin to lumbar epidural space distance [3-7]. Pre-procedural knowledge of the depth of the epidural space from the skin may serve as a guide for needle placement, particularly for less experienced operators $[8,9]$.

The skin to lumbosacral epidural space distance has recently received similar interest in veterinary anaesthesia [10-12]. A recent study in $86 \mathrm{dogs}$ identified significant positive correlations between external variables (occipital-coccygeal length (OCL) and ilium wing distance (IWD)), and the skin to epidural distance using computed tomography (CT) [12]. Multiple regression analyses have also found that the addition of a dog body condition score further improved the relationship between the external variables and the skin to epidural distance. In that study, however, only dogs with their pelvic limbs in caudal and neutral positions were investigated. It is unknown whether cranial pelvic limb positioning, as is commonly performed in dogs that are receiving an epidural, would influence this anatomical relationship. Furthermore, the derived equations from that study were based solely on correlation relationships from measurements that were obtained from the CT images, and the usefulness of the equations in predicting the true skin to lumbosacral epidural distance that are based on external measurements in vivo have yet to be determined. Ideally, a mathematical equation could be used to predict the skin to lumbosacral epidural distance and improve user accuracy in identifying the epidural space before injection in dogs.

The aims of this study were to examine whether the direction of the pelvic limb positioning would affect the skin to lumbosacral epidural distance as determined by CT measurements in canine cadavers. We also aimed to investigate whether external cadaveric measurements would be comparable to the same landmarks on the CT and assess the relationship between the mathematically derived distance and the true skin to lumbosacral epidural distance in canine cadavers. We hypothesised that the pelvic limb positioning would have no effect on the CT derived lumbosacral epidural distance, and that the CT measurements and the cadaveric measurements would be similar. We also hypothesised that the mathematical equations would have close agreement with the true skin to lumbosacral epidural distance.

\section{Materials and Methods}

\subsection{Cadavers}

A prospective experimental study was performed on 11 canine cadavers. The dogs were donated to the Anatomy Department of the School of Veterinary Science for undergraduate veterinary student teaching and were euthanised or died for reasons that were unrelated to the study. The cadavers were thawed in a cold room with a temperature of 18 degrees Celsius for approximately $48 \mathrm{~h}$ prior to analysis. The cadavers were fully developed, were not pregnant, and were free of obvious musculoskeletal disease. Any animal that was not amenable to cranial-caudal flexion of the pelvic limbs, suspected to have anatomical defects (i.e., hemi-vertebrae), or had subsequent contamination from the contrast that was outside the epidural space were excluded from analysis. The cadavers were weighed and assigned a body condition score (BCS out of 9 with 9 being obese) [13]. The sex (male or female) and the breed were also recorded.

\subsection{Procedure}

\subsubsection{Phase 1}

The cadavers were placed in sternal recumbency in the gantry of the CT. In the first phase, three pelvic limb positions were used to determine the effect of positioning on the CT derived skin to lumbosacral epidural distance (CLED) [12], with the pelvic limbs extended caudally (pulled backwards), neutral (placed on the side), and extended cranially (pulled forward). Positioning of the cadavers was performed each time by the same observers 
(ML and TCS). Scans of the entire lumbar spine and sacrum were obtained using a 16 slice multidetector CT scanner (Phillips 16 Slice, Brilliance CT V2.3; Phillips Medical Systems, Amsterdam, The Netherlands) with a $2 \mathrm{~mm}$ transverse slice thickness and $512 \times 512$ pixel matrix dimensions. For each cadaver, a total of three scans were obtained, one for each pelvic limb position (i.e., lumbosacral epidural cranial, neutral, and caudal positions were $\mathrm{LSE}_{\text {cranial }}, \mathrm{LSE}_{\text {neutral }}$ and LSE $\mathrm{Caudal}_{\text {, }}$ respectively). For each scan, a first straight line was drawn from the cranial margin of the dorsal lamina of the seventh lumbar vertebra to the cranial margin of the first sacral vertebra. This line was defined as the ligamentum flavum surrogate [12]. A secondary line was then drawn to the skin with an angle of 60 degrees to the middle of the first line and was defined as the CLED [12]. Measurements to the nearest millimetre were obtained for each of the three positional scans. The images were analysed by a single observer (TCS) and viewed on three dimensional reconstructions using a bone Hounsfield unit window (Apple Thunderbolt Display, Apple, Cupertino, CA, USA; Mac Mini, Apple; Osirix version 5.7 64-bit, Pixmeo SARL, Bernex, Switzerland).

\subsubsection{Phase 2}

The second phase of the study investigated whether the surface anatomical measurements in dog cadavers could be used as a replacement of CT measurements and predict the true skin to lumbosacral epidural distance (SLED). Surface measurements of the occipitalcoccygeal length (OCL) and ilium wing distance (IWD) were manually measured by the same observer (FMT) to the closest millimetre using a flexible measuring tape with the pelvic limbs remaining in cranial extension (Figure 1). CT measurements were subsequently made from the landmarks of the same cadavers by another observer who was unaware of the initial cadaveric measurements (TCS). The OCL was taken from the occipital protuberance to the median sacral crest of the first sacral vertebrae following the dorsal midline of the cadaver, and the same measurement was performed on the CT image from the scout view. The IWD was the distance measured between the most prominent aspects of the dorsal iliac wings on palpation on the cadaver, and between the dorsal aspects of the ilium wings on the dorsal plane window on the CT where both bony structures were first clearly visible (Figure 1). The measurements were recorded on a computerised spreadsheet for data analysis (Microsoft Excel 2011; Microsoft Corporation, Redmond, WA, USA).

For the determination of the SLED, the pelvic limbs of the cadavers remained in a cranial position and hair from the lumbosacral region was clipped. An experienced veterinary anaesthetist (TCS) performed all of the epidural injections on the cadavers. The running drip method [14] was used initially to enter the epidural space. An 18-gauge 80mm Tuohy epidural needle (B Braun, Melsungen, Germany) was inserted into the lumbosacral space. After the needle was placed through the skin, the stylet was removed and the hub of the needle was connected to a three-way tap (Becton Dickinson, Helsingborg, Sweden) attached to a raised $100 \mathrm{~mL}$ saline bag (sodium chloride 0.9\%, Baxter International Inc., Sydney, NSW, Australia) using a primed giving set ((Vetquip Niki IV infusion set, Amsino International Inc., Pomona, CA, USA). The needle was advanced until an unequivocal increase in the dripping rate was observed, at which point the three-way tap was removed from the hub of the needle and a scan was performed. The location of the tip of the needle was corroborated by a veterinary radiologist (ML), and if the needle tip was determined not to be in the epidural space, another attempt of the above procedure was performed. Each attempt was defined as a positive running drip followed by a CT scan. Epidurography was then performed in situ using diluted iodinated radiographic contrast (Omnipaque 350; GE Healthcare Australia Pty Ltd., Parramatta, NSW, Australia) with a total of $3 \mathrm{~mL}$ solution injected ( $1 \mathrm{~mL}$ contrast and $2 \mathrm{~mL}$ saline). Following the contrast injection, a CT scan was performed to confirm the presence of contrast in the epidural space, and the CLED measurement as described above in Phase 1 was later performed with the visible epidural space replacing the first line (LSE epidurography $_{\text {) }}$ (Figure 2). Once completed, straight forceps were used to clamp the skin-needle interface. A protractor was rested against the skin to measure the acute angle between the Tuohy needle and the skin. The needle and 
(a)

clamp were then removed from the cadaver and the distance from the tip of the needle to the clamp was recorded in $\mathrm{mm}$ as the SLED [10]. If epidurography indicated that contrast outside of the epidural space was present, the cadaver was excluded from further analysis.
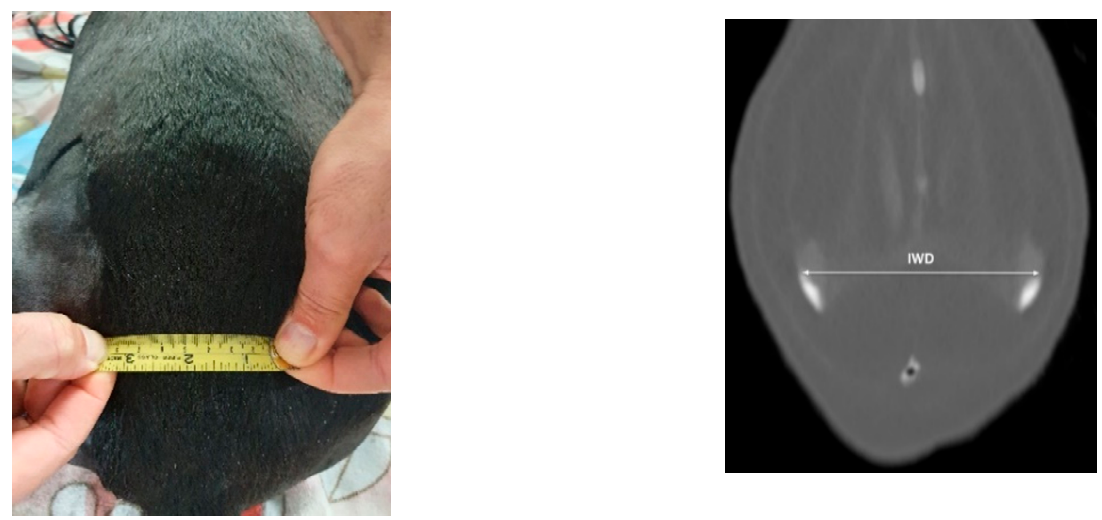

(b)
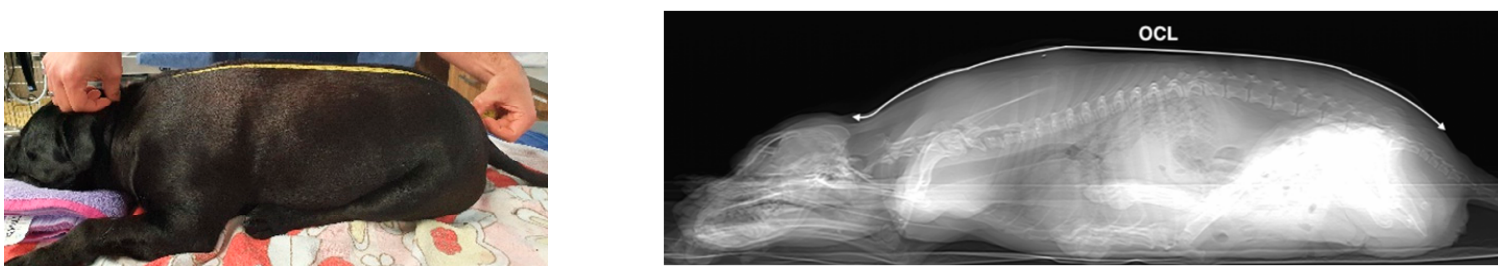

Figure 1. Representative measurements of (a) ilium wing distance (IWD), and (b) occipital-coccygeal length (OCL) obtained by surface measurements on a dog cadaver (left) and in the same dog on CT (right). Bi-directional arrows depict the landmark sites of the computed tomography (CT) images with the IWD measuring the distance between the dorsal aspects of the ilium wings on the dorsal plane window where both bony structures were first clearly visible, and the OCL from the occipital protuberance to the median sacral crest of the first sacral vertebrae following the dorsal midline of the image from the scout view.

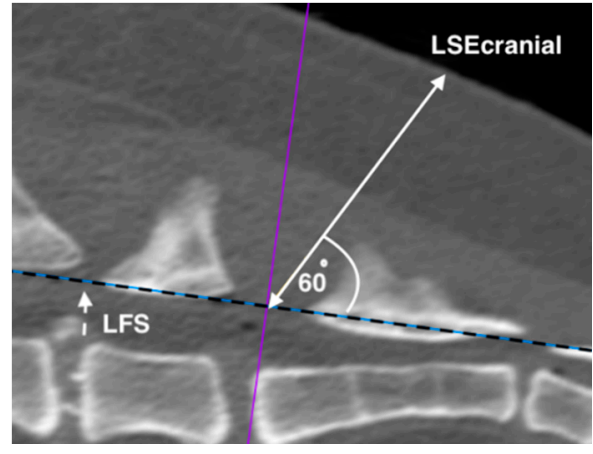

(a)

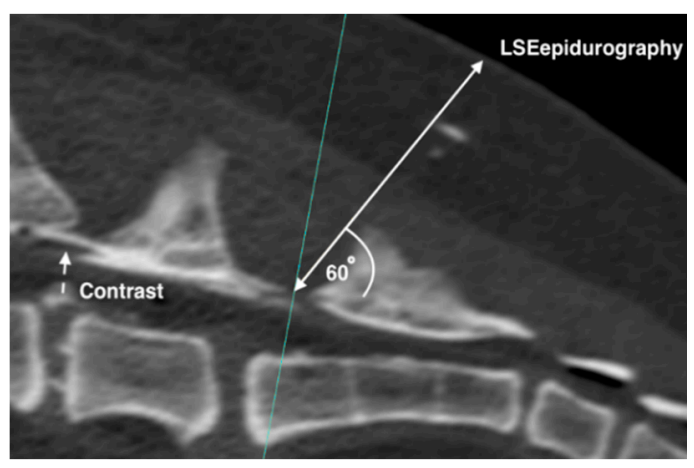

(b)

Figure 2. Computed tomography (CT) derived lumbosacral epidural distances (CLED) involving pelvic limbs in cranial extension (LSEcranial (a)), and contrast epidurography (LSEepidurography (b)). Bi-directional arrows represent the measured CLED distance at 60 degrees from either the ligamentum flavum surrogate (LFS) (hashed arrow (a)), or the epidural space confirmed by contrast epidurography (hashed arrow (b)).

\subsection{Statistical Analysis}

A sample size of 10 dogs was estimated for the detection of an $8 \mathrm{~mm}$ difference [11] between the SLED and two mathematically derived lumbosacral epidural space distances, with a variance of 25 , loss of $15 \%$ and power of $90 \%$ [15]. The mathematical equation for 
predicting the SLED were obtained by using the BCS with the OCL or IWD derived from our previous study [12]:

$$
\begin{aligned}
& \text { SLED }_{\text {equation } 1}=7.3+0.05^{*} \mathrm{OCL}+16.45^{*} \mathrm{BCS} \\
& \mathrm{SLED}_{\text {equation2 }}=3.5+0.56^{*} \mathrm{IWD}+16.6^{*} \mathrm{BCS}
\end{aligned}
$$

The BCS was further classified as binominal $(0=$ less than or equal to BCS $5 / 9$, and $1=$ greater than BCS 5/9) as published previously [12]. Measurements were recorded on a computerized spreadsheet (Microsoft Excel 2011; Microsoft Corporation, Redmond, WA, USA), and transferred to statistical software program R, version 3.6.1 for Windows 10 (The R Foundation for Statistical Computing, http: www.Rproject.org, last accessed 18 July 2021, Vienna, Austria).

For Phase 1, the CLED for $\mathrm{LSE}_{\text {cranial }}, \mathrm{LSE}_{\text {neutral}}$, and $\mathrm{LSE}_{\text {caudal }}$ were compared. For Phase 2, the cadaveric OCL and IWD were compared with their respective CT measurements, and the LSE $\mathrm{E}_{\text {epidurography }}$ was compared with $\mathrm{LSE}_{\text {cranial }}$ to validate the ligamentum flavum surrogate. The crude values were examined for normality using the Shapiro-Wilk test. When a normal data distribution was found, a one-way analysis of variance or Student's t-test was used where appropriate. If the data were non-normally distributed, the Mann-Whitney U test was used. Correlation and concordance relationships were determined to validate the mathematical equations using the cadaveric measurements with the SLED. Correlation was expressed as positive or negative values of Pearson's correlation coefficient $(r)$. Proportion of fit $\left(R^{2}\right)$, F statistic for the predictability variable of the outcome, and $\beta$ weights for increase in the variable for each standard deviation were reported. Relationships were examined graphically by using the crude values, and the linearity of residuals and fitted values were assessed in R. Concordance was determined by assessing the level of agreement between the predicted variables (Equations (1) and (2)) and a gold standard (SLED) by calculating Lin's concordance coefficient (CCC) and concordance line agreement bias (c.b.), where $C C C=1$ indicates perfect agreement; 0 : no agreement; -1 : reverse agreement [16]. Values between 0 and $0.29,0.3$ and $0.49,0.5$ and 0.69 , and 0.7 and 1.0 were considered to signify very weak, weak, moderate, and strong for both $r$ and CCC, respectively [17]. Statistical significance was set at $p<0.05$.

\section{Results}

\subsection{Phase 1}

A total of 11 cadavers met the inclusion criteria, and no cadavers were excluded. Summary descriptive data for sex, weight, and breed are provided in Table 1. Phase 1 analysis of the pelvic limbs in caudal, neutral, and cranial positions demonstrated no effect on the CLED $(p=0.3084)$.

Table 1. Descriptive information for the 11 canine cadavers, the CT derived lumbosacral epidural space distance (CLED) based on three pelvic limb positions (Phase 1), with the predictor and the outcome values for correlation and concordance

\begin{tabular}{|c|c|c|c|c|c|c|c|c|c|c|c|c|}
\hline \multirow{3}{*}{ ID } & \multirow{3}{*}{ Sex } & \multirow{3}{*}{$\begin{array}{c}\text { Weight } \\
\text { (kg) }\end{array}$} & \multirow{3}{*}{$\frac{\text { BCS }}{19}$} & \multirow{3}{*}{ Breed } & \multicolumn{3}{|c|}{ Phase 1 (In Millimetres) } & \multicolumn{5}{|c|}{ Phase 2 (In Millimetres) } \\
\hline & & & & & \multicolumn{3}{|c|}{ CLED } & OCL & IWD & $\begin{array}{l}\text { Equation } \\
\text { (1) }\end{array}$ & $\begin{array}{l}\text { Equation } \\
\text { (2) }\end{array}$ & SLED \\
\hline & & & & & Caudal & Neutral & Cranial & \multicolumn{2}{|c|}{ Cadaver/CT } & & & \\
\hline 1 & $\mathrm{M}$ & 15 & 5 & $\begin{array}{l}\text { Staffordshire } \\
\text { bull terrier }\end{array}$ & 43 & 43 & 34 & $565 / 510$ & $80 / 59$ & 35.6 & 48.3 & 34 \\
\hline 2 & $\mathrm{~F}$ & 23.5 & 7 & $\begin{array}{l}\text { Staffordshire } \\
\text { bull terrier }\end{array}$ & 59 & 53 & 46 & $630 / 593$ & $90 / 63$ & 55.3 & 70.5 & 49 \\
\hline 3 & $\mathrm{~F}$ & 20.3 & 6 & $\begin{array}{l}\text { Staffordshire } \\
\text { bull terrier }\end{array}$ & 57 & 62 & 52 & $580 / 524$ & $95 / 61$ & 52.8 & 73.3 & 51 \\
\hline 4 & M & 29.9 & 4 & Greyhound & 36 & 36 & 29 & $950 / 941$ & $96 / 102$ & 54.8 & 57.3 & 30 \\
\hline 5 & $\mathrm{~F}$ & 34.1 & 7 & English bulldog & 59 & 63 & 56 & $760 / 687$ & $85 / 72$ & 61.8 & 67.7 & 61 \\
\hline
\end{tabular}
evaluation (Phase 2). 
Table 1. Cont.

\begin{tabular}{|c|c|c|c|c|c|c|c|c|c|c|c|c|}
\hline \multirow[b]{2}{*}{ ID } & \multirow[b]{2}{*}{ Sex } & \multirow[b]{2}{*}{$\begin{array}{c}\text { Weight } \\
\text { (kg) }\end{array}$} & \multirow{2}{*}{$\frac{\text { BCS }}{19}$} & \multirow[b]{2}{*}{ Breed } & \multicolumn{3}{|c|}{ Phase 1 (In Millimetres) } & \multicolumn{5}{|c|}{ Phase 2 (In Millimetres) } \\
\hline & & & & & & CLED & & OCL & IWD & $\begin{array}{c}\text { Equation } \\
\text { (1) }\end{array}$ & $\begin{array}{l}\text { Equation } \\
\text { (2) }\end{array}$ & SLED \\
\hline & & & & & Caudal & Neutral & Cranial & Cadav & /CT & & & \\
\hline 6 & M & 14.1 & 4 & Beagle & 42 & 41 & 36 & $640 / 609$ & $70 / 66$ & 39.3 & 42.7 & 41 \\
\hline 7 & M & 9.6 & 2 & Crossbred & 22 & 22 & 17 & $560 / 543$ & $60 / 56$ & 35.3 & 37.1 & 24 \\
\hline 8 & M & 14.1 & 4 & Beagle & 34 & 34 & 28 & $670 / 615$ & $80 / 66$ & 40.8 & 48.3 & 31 \\
\hline 9 & $\mathrm{~F}$ & 9.2 & 5 & French bulldog & 33 & 33 & 29 & $455 / 454$ & $88 / 53$ & 30.1 & 52.8 & 32 \\
\hline 10 & M & 11.2 & 5 & Kelpie & 41 & 40 & 32 & $550 / 527$ & $65 / 66$ & 34.8 & 39.9 & 33 \\
\hline 11 & M & 17.5 & 4 & $\begin{array}{l}\text { Staffordshire } \\
\text { bull terrier }\end{array}$ & 40 & 37 & 30 & $730 / 645$ & $90 / 63$ & 43.8 & 53.9 & 29 \\
\hline
\end{tabular}

ID: Cadaver identification; kg: weight in kilograms; Phase 1-the CT derived lumbosacral epidural space measurements of pelvic limbs in the caudal, neutral, and cranial positioning with the cadavers in sternal recumbency; Phase 2: BCS- the body condition score out of 9; OCL: occipital-coccygeal length; IWD: ilium wing distance; Equation (1)-the lumbosacral epidural space derived from the cadaveric OCL using the equation $[=7.3+0.05(\mathrm{OCL})+16.45(\mathrm{BCS})]$; Equation (2) - the lumbosacral epidural space derived from the cadaveric IWD using [= $3.5+0.56(\mathrm{IWD})+16.6(\mathrm{BCS})]$; SLED: the true skin to lumbosacral epidural distance confirmed with epidurography.

\subsection{Phase 2}

The individual BCS, SLED, OCL, and IWD (both cadaveric and CT), and the mathematically derived lumbosacral epidural distances using Equations (1) and (2) are shown in Table 1 . The cadaveric and CT measurements were different for the IWD $(p=0.0150)$, but not for the OCL $(p=0.3)$.

The contrast epidurography confirmed the SLED in all dogs. Of the dogs, eight required one attempt, two dogs required two attempts and one dog required three attempts at needle placement, while the final angle of the Tuohy needle projection ranged from 60 to 110 degrees. The CLED for the $\mathrm{LSE}_{\text {cranial }}$ and the $\mathrm{LSE}_{\text {epidurography }}$ were not different $(p=0.6037)$.

The correlation and concordance of mathematical equations using cadaveric measurements with the SLED are presented in Table 2. Both demonstrated strong correlations with the SLED (Equation (1): $r=0.7196, p=0.0125$; Equation (2): $r=0.7590, p=0.0068$ ). However, the level of agreement was greater for Equation $(1)(C C C=0.6061 ; p=0.0125)$ than for Equation (2) $(C C C=0.3752 ; p=0.0068)$. Equation (1) also demonstrated a closer fit to the concordance line (c.b. 0.8422), compared with Equation (2) (c.b. 0.4960).

Table 2. Correlation and concordance relationships between the true skin to lumbosacral epidural distance (SLED), and two mathematically derived lumbosacral epidural distances from 11 canine cadavers.

\begin{tabular}{|c|c|c|c|c|c|c|c|c|c|}
\hline $\begin{array}{c}\text { SLED } \\
\text { Prediction }\end{array}$ & $r, 95 \% \mathrm{CI}$ & $\mathbf{P}_{r}$ & $R^{2}$ & Intercept & $\beta$ & $\mathbf{F}$ & $\mathbf{P}_{\mathbf{R}^{2}}$ & CСC, $95 \% \mathrm{CI}$ & c.b \\
\hline Equation (1) & $\begin{array}{c}0.7196 \\
0.2107-0.9217\end{array}$ & 0.0125 & 0.5179 & 19.0621 & 0.6620 & 9.668 & 0.0125 & $\begin{array}{c}0.6061 \\
0.1471-0.8503\end{array}$ & 0.8422 \\
\hline Equation (2) & $\begin{array}{c}0.7590 \\
0.2913-0.9340\end{array}$ & 0.0068 & 0.5755 & 22.7683 & 0.8225 & 12.2 & 0.0068 & $\begin{array}{c}0.3763 \\
0.0590-0.6246\end{array}$ & 0.4960 \\
\hline
\end{tabular}

The two mathematical equations: Equation (1) [SLED = 7.3 + 0.05(OCL) + 16.45(BCS)], and Equation (2) [SLED = 3.5 + 0.56(IWD) + 16.6(BCS)], where (BCS) was (0) for body condition score less than or equal to 5/9 and (1) for greater than 5/9, OCL: Occipital-coccygeal length (mm); IWD: ilium wing distance (mm); $r$ : Pearson's correlation coefficient; $95 \% \mathrm{CI}$ : 95\% confidence interval; $\mathrm{P}_{r}: p$ value for $r$; $R^{2}$ : proportion of fit of the variable; F: predictability variable, $\beta$ : weight for the increase in the variable for each standard deviation; $\mathrm{P}_{\mathrm{R}}^{2}: p$ value for $R^{2} ; \beta$ : predictability variability of the outcome; CCC: Lin's concordance coefficient; c.b: agreement bias for deviation from the best fit line of 45 degrees. No deviation occurs when c.b. $=1$.

\section{Discussion}

This study supports the hypothesis that cranial extension of the pelvic limbs in canine cadavers does not affect the CT derived skin to lumbosacral epidural distance when compared with neutral and caudal positions. The cadaveric and CT derived measurements were different for the IWD, but not for the OCL. Furthermore, there was no statistical difference in the $\mathrm{CT}$ derived skin to lumbosacral epidural distance when using the liga- 
mentum flavum surrogate and contrast epidurography. Both Equation (1) (using OCL) and Equation (2) (using IWD) correlated with the true skin to lumbosacral epidural space distance, but Equation (2) had higher agreement.

Dogs undergoing clinical epidural placement are frequently placed in sternal recumbency with their pelvic limbs in cranial extension [18,19], and it is possible that the lumbosacral anatomical relationships would be influenced by pelvic limb positioning. Previous studies indicate that dog cadavers with cranially placed pelvic limbs have increased lumbosacral interlaminar distances on the $\mathrm{CT}$ when compared with pelvic limbs in the caudal placement $[20,21]$, while the mid-laminar L5-L6 distances in dogs positioned in a sternal kyphotic position with the pelvic limbs extended cranially were greater than in neutral positioning [22]. Our previous research showed that the CT derived skin to lumbosacral epidural distances between pelvic limbs in neutral and caudal positioning were not statistically different [12], and it was unknown whether the pelvic limbs in cranial extension would change this relationship. The results from Phase 1 of this study suggest that cranial extension of the pelvic limbs and the other positions investigated are unlikely to affect the CLED in this population of cadavers. However, there should be caution in extrapolating this relationship to live dogs as the degree of pelvic limb extension may be greater in cadavers than in live dogs. For example, hip extension may be restricted by a disease processes such as osteoarthritis [21]. Additionally, the intrinsic anatomy of the epidural space is maintained by physiological pressures and venous distension, which is lost immediately after death [23]. Further prospective studies in live anaesthetised dogs are necessary to validate the results from this cadaveric study for clinical use.

Epidurography is considered the gold standard method for confirming the epidural space in both dogs and humans [24-26], but the use of contrast agents, the cost, and accessibility to advanced imaging limit its use in clinical veterinary practice [27,28]. Epidurography was chosen as the standard for comparison in this study because this method is the most accurate for confirming the epidural placement of a needle [29]. Correct needle placement was essential in identifying the SLED in the cadavers and corroborating the $\mathrm{CT}$ derived mathematical equations. In a previous clinical study, the loss-of resistance method was used to determine the depth of the skin to epidural space in anaesthetised dogs [10]. However, this technique has been associated with a procedural failure rate of up to $32 \%$ [30] and was considered inadequate in confirming the epidural space when used alone [29]. The current study used the running drip method as a guide prior to epidurography. The running drip method was associated with a success rate of $90 \%$ in the detection of the lumbosacral epidural space, but may not differentiate between the intrathecal and epidural spaces [31]. If an alternative technique to epidurography was used as a confirmation for epidural space placement in cadavers, the internal validity of the results may have been reduced.

The results from this study are limited to cadavers and cannot imply any clinical improvement in the detection of the epidural space of dogs in vivo, and the efficacy of performing an epidural was not an aim of this study. Our secondary hypothesis was specific for determining the correlation and agreement between the mathematical equations and the SLED. In humans, predictive mathematical models have been suggested to be beneficial prior to epidural needle placement [6,7,32-34]. In particular, mathematical models have been used for people considered to be at risk of a difficult epidural due to deeper distances $[9,35,36]$. In morbidly obese parturient women, the combination of an ultrasound with pre-procedural epidural depth equations that are determined from height and weight variables improved the success rate of the epidural catheter placement than with ultrasonography alone [9]. However, the equations that were generated from individual studies have not been validated to other patient populations, therefore, their use is limited to within the same study population [8]. Conversely, the present study validated existing equations by demonstrating good agreement and correlation with an alternative unrelated study population [12]. We hypothesised that our previously reported equations using CT derived external morphometric variables would have a high degree of 
agreement with the SLED using dog cadaveric measurements. However, the CT derived measurement was statistically different to the cadaveric measurements when the IWD was examined. In our study, the dorsal aspects of the iliac crests were difficult to palpate in dogs with a higher BCS. It is possible that the IWD was overestimated in some cadavers due to extra subcutaneous fat cover over the iliac crests, resulting in a wider distribution of datapoints and the lower concordance reported for Equation (2). Alternatively, the measurements of the OCL in both cadaveric and CT derived distances were not different. The cadaveric measurements were performed over two distinct landmarks, the occipital protuberance and the base of the first sacral vertebrae, both of which were easily palpable in all cadavers regardless of the BCS. The practical ease of measuring the OCL and the higher concordance coefficient suggests that using the OCL (Equation (1)) may be a preferred method in predicting the SLED. Further prospective studies in anaesthetised animals can be used to determine whether mathematical equations to predict depth would truly improve the efficacy in epidural space identification.

There were some limitations to this study. Thawed cadavers were used, and the results should not be extrapolated to live dogs. The SLED in cadavers may be greater due to the absence of epidural pressures that are generated by the lymphatic and circulatory systems in the abdominal and thoracic cavities [23]. The effect of freeze-thawing may also have altered the integrity of epidural anatomical structures due to the collapse of the dural sac after freezing [37]. Another limitation was that this study was designed to validate previous mathematical equations that were only formulated for dogs in sternal recumbency, and the results cannot be applied to other recumbencies. A consideration from the results is the clinical perceptible difference that is acceptable between the mathematical equations and the SLED. The sample size calculations suggested that ten dogs were required to detect an $8 \mathrm{~mm}$ difference, and while this number may seem small, it was appropriate for demonstrating a meaningful clinical difference [11] and for concordance analysis [16] The equations used in this study were derived from multivariable analysis involving two external morphometric variables (OCL, IWD), and the BCS. A moderate proportion of fit was found from both Equation (1) $\left(R^{2}=0.5179\right)$ and Equation $(2)\left(R^{2}=0.5755\right)$, which showed that some variation was unaccounted for in the models. While increasing the number of variables may improve this relationship, it adds complexity and restricts the clinical applicability of these equations. In addition, while fat content in overweight animals is not evenly distributed, the use of the BCS makes the body fat distribution irrelevant, while the binomial classification further reduces subjectivity of multiple BCS categories and improves the practical use of the equations. Some breeds were over-represented in our study population of cadavers; however, the mathematical equations were originally developed incorporating different dog breeds [12], and it would be reasonable to assume that the external morphometric variables and the body condition score would capture some differences in breed conformation.

\section{Conclusions}

In conclusion, cranial extension of the pelvic limbs had no effect on the CT derived skin to epidural distance. Mathematical equations were highly correlated with the SLED and using the OCL showed a higher level of agreement compared with the IWD. Further clinical studies in anaesthetised dogs are required to determine the usefulness of this information prior to epidural needle placement.

Author Contributions: T.C.S. contributed to conceptualization, methodology, validation, formal analysis, investigation, data curation, and writing and editing of the original and final manuscript. M.S. contributed to supervision, writing review, and editing. M.P.Y.L. contributed to methodology, software and image analysis, and final review of the manuscript. F.M.-T. contributed to conceptualization, methodology, validation, formal analysis, data curation, review, and final editing of the manuscript. All authors have read and agreed to the published version of the manuscript.

Funding: This research received no external funding. 
Institutional Review Board Statement: Ethical review and approval were waived for this study. The cadavers were provided for undergraduate teaching and euthanised for reasons unrelated to the study.

Data Availability Statement: Data provided on request.

Conflicts of Interest: The authors declare no conflict of interest.

\section{References}

1. Kim, J.H.; Song, S.Y.; Kim, B.J. Predicting the difficulty in performing a neuraxial blockade. Korean J. Anesthesiol. 2011, 61, 377-381. [CrossRef]

2. Tawfik, M.; Atallah, M.M.; Elkharboutly, W.S.; Allakkany, N.S.; AbdelKhalek, M. Does Preprocedural Ultrasound Increase the First-Pass Success Rate of Epidural Catheterization Before Cesarean Delivery? A Randomized Controlled Trial. Anesthesia Analg. 2017, 124, 851-856. [CrossRef] [PubMed]

3. Eley, V.; Chin, A.; Sekar, R.; Donovan, T.; Krepska, A.; Lawrence, M.; Bell, S.; Ralfe, K.; McGrath, S.; Webb, L.; et al. Increasing body mass index and abdominal subcutaneous fat thickness are associated with increased skin-to-epidural space distance in pregnant women. Int. J. Obstet. Anesthesia 2019, 38, 59-65. [CrossRef] [PubMed]

4. Ravi, K.K.; Kaul, T.K.; Kathuria, S.; Gupta, S.; Khurana, S. Distance from Skin to Epidural Space: Correlation with Body Mass Index (BMI). J. Anaesthesiol. Clin. Pharmacol. 2011, 27, 39-42. [PubMed]

5. Adachi, Y.U.; Sanjo, Y.; Sato, S. The epidural space is deeper in elderly and obese patients in the Japanese population. Acta Anaesthesiol. Scand. 2007, 51, 731-735. [CrossRef] [PubMed]

6. Sharma, V.; Swinson, A.K.; Hughes, C.; Mokashi, S.; Russell, R. Effect of ethnicity and body mass index on the distance from skin to lumbar epidural space in parturients. Anaesthesia 2011, 66, 907-912. [CrossRef] [PubMed]

7. Stamatakis, E.; Moka, E.; Siafaka, I.; Argyra, E.; Vadalouca, A. Prediction of the Distance from the Skin to the Lumbar Epidural Space in the Greek Population, Using Mathematical Models. Pain Pract. 2005, 5, 125-134. [CrossRef] [PubMed]

8. Ong, J.; Kirthinanda, D.; Loh, S.K.N.; Sng, B.L.; Dinoo, K. Strategies to reduce neuraxial analgesia failure during labour. Trends Anaesth. Crit. Care 2016, 7-8, 41-46. [CrossRef]

9. Singh, S.; Wirth, K.M.; Phelps, A.L.; Badve, M.H.; Shah, T.H.; Sah, N.; Vallejo, M.C. Epidural Catheter Placement in Morbidly Obese Parturients with the Use of an Epidural Depth Equation prior to Ultrasound Visualization. Sci. World J. 2013, 2013, 1-6. [CrossRef] [PubMed]

10. Iseri, T.; Nishimura, R.; Nagahama, S.; Nakagawa, T.; Fujimoto, Y.; Sasaki, N. Distance between the skin and the lumbosacral epidural space in dogs. Jpn. J. Vet. Res. 2019, 67, 35-40. [CrossRef]

11. Da Silva, L.C.; Pacheco, P.F.; Sellera, F.; Futema, F.; Cortopassi, S. The use of ultrasound to assist epidural injection in obese dogs. Vet. Anaesth. Analg. 2020, 47, 137-140. [CrossRef]

12. Sun, T.C.; Makara, M.; Martinez-Taboada, F. Computed Tomography-Derived Occipital-Coccygeal Length and Ilium Wing Distance Correlates with Skin to Epidural and Intrathecal Depths in Dogs. Vet. Sci. 2020, 7, 196. [CrossRef] [PubMed]

13. Laflamme, D.P. Development and validation of a body condition score system for dogs. Canine Pract. 1997, 22, 10-15.

14. Martinez-Taboada, F.; Redondo, J.I. Comparison of the hanging-drop technique and running-drip method for identifying the epidural space in dogs. Vet. Anaesth. Analg. 2017, 44, 329-336. [CrossRef]

15. Pita Fernández, S. Clinical Epidemiology and Biostatistics Unit. Complexo Hospitalario Universitario de A Coruña. Available online: https://www.fisterra.com/mbe/investiga/9muestras/9muestras2.asp (accessed on 19 July 2021).

16. Lin, L.I.-K. Assay Validation Using the Concordance Correlation Coefficient. Biometrics 1992, 48, 599. [CrossRef]

17. Altman, D.G. Practical Statistics for Medical Research. In Relation between Two Continuous Variables; Chapman \& Hall/CRC: London, UK, 2006; pp. 317-318.

18. Campoy, L. Epidural and spinal anaesthesia in the dog. Practice 2004, 26, 262-269. [CrossRef]

19. Jones, R. Epidural Analgesia in the Dog and Cat. Vet. J. 2001, 161, 123-131. [CrossRef] [PubMed]

20. Panti, A.; Greenhalgh, S.N.; Longo, M.; Liuti, T. The effect of recumbency and hindlimb position on the lumbosacral interlaminar distance in dogs: A cadaveric computed tomography study. Vet. Anaesth. Analg. 2018, 45, 802-810. [CrossRef] [PubMed]

21. Di Concetto, S.; Mandsager, R.E.; Riebold, T.W.; Stieger-Vanegas, S.M.; Killos, M. Effect of hind limb position on the craniocaudal length of the lumbosacral space in anesthetized dogs. Vet. Anaesth. Analg. 2012, 39, 99-105. [CrossRef]

22. Puggioni, A.; Arnett, R.; Clegg, T.; Glyde, M.; Tobin, E.; McAllister, H. Influence Of Patient Positioning On The L5-L6 Mid-Laminar Distance. Vet. Radiol. Ultrasound 2006, 47, 449-452. [CrossRef] [PubMed]

23. Kawalilak, L.T.; Tucker, R.L.; Greene, S.A. Use Of Contrast-Enhanced Computed Tomography To Study The Cranial Migration Of A Lumbosacral Injectate In Cadaver Dogs. Vet. Radiol. Ultrasound 2015, 56, 570-574. [CrossRef] [PubMed]

24. Bartynski, W.S.; Grahovac, S.Z.; Rothfus, W.E. Incorrect Needle Position during Lumbar Epidural Steroid Administration: Inaccuracy of Loss of Air Pressure Resistance and Requirement of Fluoroscopy and Epidurography during Needle Insertion. Am. J. Neuroradiol. 2005, 26, 502-505. [PubMed]

25. Johnson, B.A.; Schellhas, K.P.; Pollei, S.R. Epidurography and Therapeutic Epidural Injections: Technical Considerations and Experience with 5334 Cases. Am. J. Neuroradiol. 1999, 20, 697-705. 
26. Liotta, A.P.; Girod, M.; Peeters, D.; Sandersen, C.; Couvreur, T.; Bolen, G. Clinical effects of computed tomography-guided lumbosacral facet joint, transforaminal epidural, and translaminar epidural injections of methylprednisolone acetate in healthy dogs. Am. J. Vet. Res. 2016, 77, 1132-1139. [CrossRef]

27. Scarabelli, S.; Cripps, P.; Rioja, E.; Alderson, B. Adverse reactions following administration of contrast media for diagnostic imaging in anaesthetized dogs and cats: A retrospective study. Vet. Anaesth. Analg. 2016, 43, 502-510. [CrossRef] [PubMed]

28. Barone, G.; Ziemer, L.S.; Shofer, F.S.; Steinberg, S.A. Risk factors associated with development of seizures after use of iohexol for myelography in dogs: 182 cases (1998). J. Am. Vet. Med. Assoc. 2002, 220, 1499-1502. [CrossRef] [PubMed]

29. Adami, C.; Gendron, K. What is the evidence? The issue of verifying correct needle position during epidural anaesthesia in dogs. Vet. Anaesth. Analg. 2017, 44, 212-218. [CrossRef] [PubMed]

30. Sarotti, D.; Rabozzi, R.; Franci, P. Comparison of epidural versus intrathecal anaesthesia in dogs undergoing pelvic limb orthopaedic surgery. Vet. Anaesth. Analg. 2015, 42, 405-413. [CrossRef] [PubMed]

31. Martinez-Taboada, F.; Otero, P.E.; Laredo, F.; Belda, E. Identification of the sacrococcygeal epidural space using the nerve stimulation test or the running-drip method in dogs. Vet. Anaesth. Analg. 2020, 47, 385-390. [CrossRef]

32. Adegboye, M.; Bolaji, B.; Ibraheem, G. The Correlation between Body Mass Index on The Length From Skin To Lumbar Epidural Space In Nigerian Adults. J. West Afr. Coll. Surg. 2017, 7, 113-127. [PubMed]

33. Kao, M.; Tsai, S.; Chang, W.; Liu, H.; Hsieh, Y.; Hu, J.; Mok, M. Prediction of the distance from skin to epidural space for low-thoracic epidural catheter insertion by computed tomography. Br. J. Anaesth. 2004, 92, 271-273. [CrossRef] [PubMed]

34. Sutherland, G.P.; Shaw, M.; Broom, M.A. Predicting epidural space depth in an obstetric population using patient demographics: An observational study of 1534 patients. Eur. J. Anaesthesiol. 2021, 38, 794-796. [CrossRef] [PubMed]

35. Kim, K.; Recku, G.; Fluder, E.; Corsino, A. The distance from the skin to the epidural space in morbidly obese patients undergoing bariatric surgery. Reg. Anaesth. Pain Med. 2003, 28, A4.

36. Clinkscales, C.; Greenfield, M.; Vanarase, M.; Polley, L. An observational study of the relationship between lumbar epidural space depth and body mass index in Michigan parturients. Int. J. Obstet. Anesthesia 2007, 16, 323-327. [CrossRef] [PubMed]

37. Cima, D.S.; Credie, L.D.F.G.A.; Futema, F.; Luna, S.P.L. Lumbar Epidural: Anatomical and Clinical Study in Dogs Submitted to Ovariohysterectomy. Front. Vet. Sci. 2020, 7, 7. [CrossRef] [PubMed] 